\title{
Medievalista
}

Online

$28 \mid 2020$

Número 28

\section{Jornadas Internacionais}

\section{Terra, Pedras e Cacos do Garb al-Andalus}

\section{Jornadas Internacionais}

Earth, Stones and Sherds of Gharb al-Andalus. International Congress

\section{Isabel Cristina Fernandes}

\section{(2) OpenEdition \\ Journals}

\section{Edição electrónica}

URL: http://journals.openedition.org/medievalista/3428

DOI: 10.4000/medievalista.3428

ISSN: 1646-740X

\section{Editora}

Instituto de Estudos Medievais - FCSH-UNL

\section{Edição impressa}

Paginação: 493-508

\section{Refêrencia eletrónica}

Isabel Cristina Fernandes, «Terra, Pedras e Cacos do Garb al-Andalus», Medievalista [Online], 28 | 2020, posto online no dia 01 julho 2020, consultado o 24 março 2021. URL: http://journals.openedition.org/ medievalista/3428 ; DOI: https://doi.org/10.4000/medievalista.3428

Este documento foi criado de forma automática no dia 24 março 2021.

\section{cc) (i) (8)}

Mediavalista está licenciado com uma Licença Creative Commons - Atribuição-NãoComercial 4.0 Internacional. 
Jornadas Internacionais

\section{Terra, Pedras e Cacos do Garb al- Andalus}

Jornadas Internacionais

Earth, Stones and Sherds of Gharb al-Andalus. International Congress

\section{Isabel Cristina Fernandes}

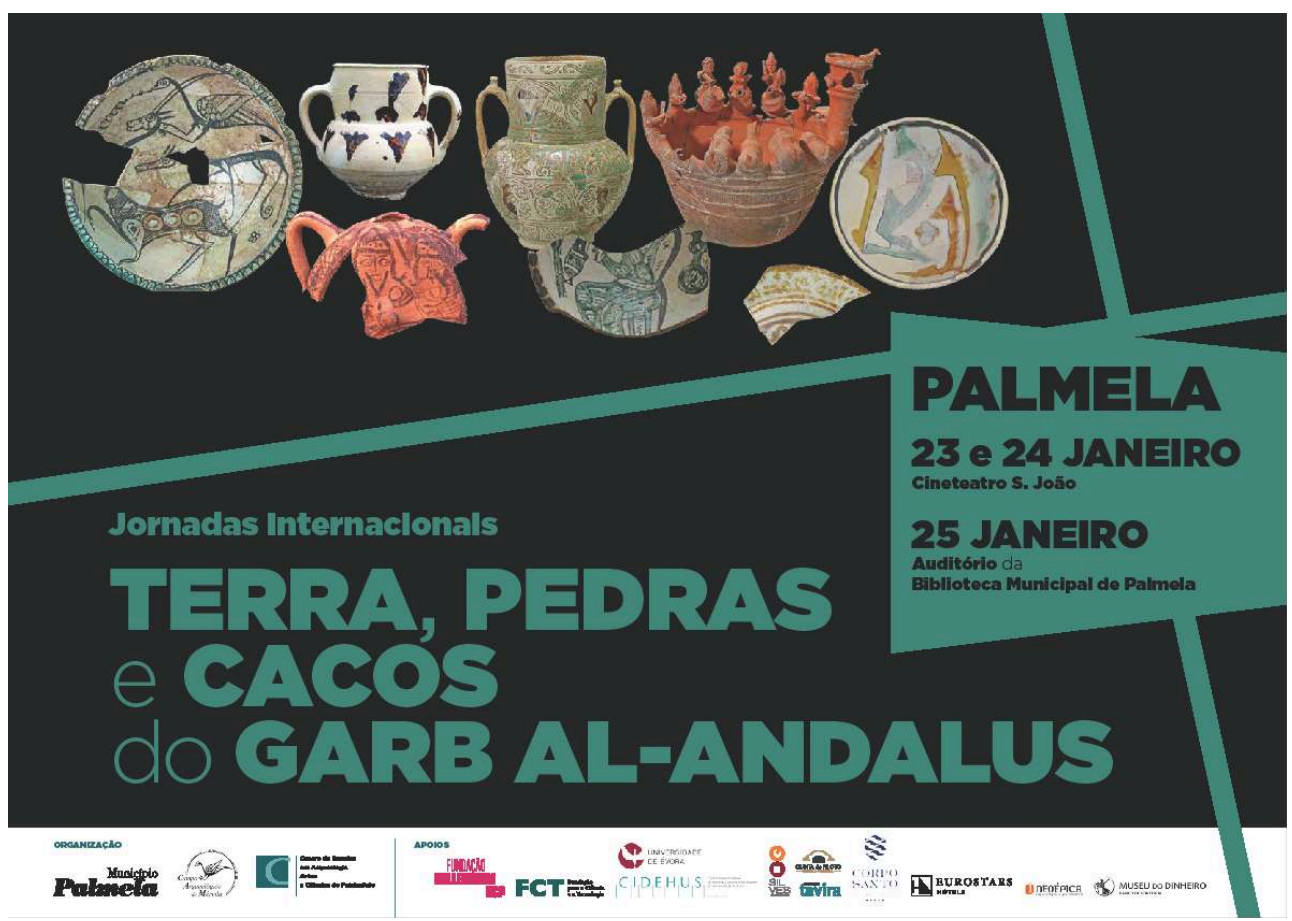

1 Entre 23 e 25 de janeiro de 2020 realizou-se em Palmela as Jornadas Internacionais “Terra, Pedras e Cacos do Garb al-Andalus”, com coordenação científica do Grupo CIGA ${ }^{1}$ e organização, em parceria, do Município de Palmela e do Campo Arqueológico de Mértola. 
2 A ideia de realizar esta reunião partiu do Grupo CIGA que, doze anos após a sua criação e na senda das regulares investigação e publicação de estudos em torno da cerâmica medieval islâmica, considerou prioritário o relançamento do debate sobre este período. Vários aspetos contribuíram para a constatação dessa necessidade: o grande número de escavações de emergência do período islâmico nas últimas décadas; a reduzida divulgação dos resultados; algum esmorecimento do interesse público por este período histórico, depois da visibilidade do final da centúria passada; a necessidade de um incremento do diálogo entre a Arqueologia e a História.

3 As jornadas foram estruturadas em quatro sessões: Sessão 1 - Revelações e novas abordagens sobre o Garb no século XXI; Sessão 2 - Arqueologia preventiva: transformar salvaguarda em conhecimento do Garb al-Andalus; Sessão 3 - O Garb e o Mediterrâneo; Sessão 4 - Da história à arqueologia e da arqueologia à história do Garb al-Andalus. Seguindo este elenco temático, foi elaborado um programa que incluiu oradores convidados, comunicantes e autores de posters.

4 Na sessão inaugural dos trabalhos teve lugar uma breve evocação do historiador francês Christophe Picard, vinte anos após a publicação da sua obra de referência para o estudo do Garb: Le Portugal Musulman (VIII ${ }^{\mathrm{e}-\mathrm{XIII}}{ }^{\mathrm{e}}$ siècle). L'Occident d'al-Andalus sous domination islamique, editada pela Maisonneuve \& Larose, Paris. Pioneiro na construção de uma história em diálogo com a arqueologia, impulsionou a investigação do período islâmico em Portugal e fê-lo insistindo no cruzamento da informação documental escrita com a leitura das materialidades.

5 A comunicação de abertura coube ao Grupo CIGA, que após um breve historial do grupo e do trabalho desenvolvido, apresentou doze peças do período islâmico, selecionadas por cada um dos membros, segundo critérios diversos.

6 A Sessão 1 iniciou-se com abordagens histórico-arqueológicas de Manuel Luís Real e Paulo Almeida Fernandes: a primeira centrada no contexto político da presúria de Coimbra de 878, com interpretações coadjuvadas pela análise de um capitel e duas epígrafes; a segunda, sobre as dinâmicas artísticas moçárabes, questionando períodos e lugares de desenvolvimento para, a partir de materialidades de Lisboa, traçar uma síntese sobre aspetos vários da população moçárabe do Garb. Catarina Tente prosseguiu esta sessão com inferências de âmbito económico-social, de gestão do território e de articulação dos poderes, no séc. $\mathrm{X}$, a partir dos dados do registo arqueológico na região fronteiriça da Beira Alta. $O$ estudo do território e do povoamento da diocese/ kura de Ossónoba/Ocsonoba, entre a antiguidade tardia e o período islâmico, foi objeto da análise histórico-arqueológica de Helena Catarino, com incidência particular nos castelos de Alcoutim e Relíquias. As sínteses desta sessão seriam completadas pela comunicação de Maria Antónia Martínez Núñez e Pilar Delgado Blasco, uma reflexão sobre a importância da epigrafia para o conhecimento do Garb, através do conhecimento que proporciona a vários níveis: cronológico, antroponímico, toponímico, ideológico, político, cultural, matizando com frequência os dados fornecidos pela arqueologia ou pelos textos. 


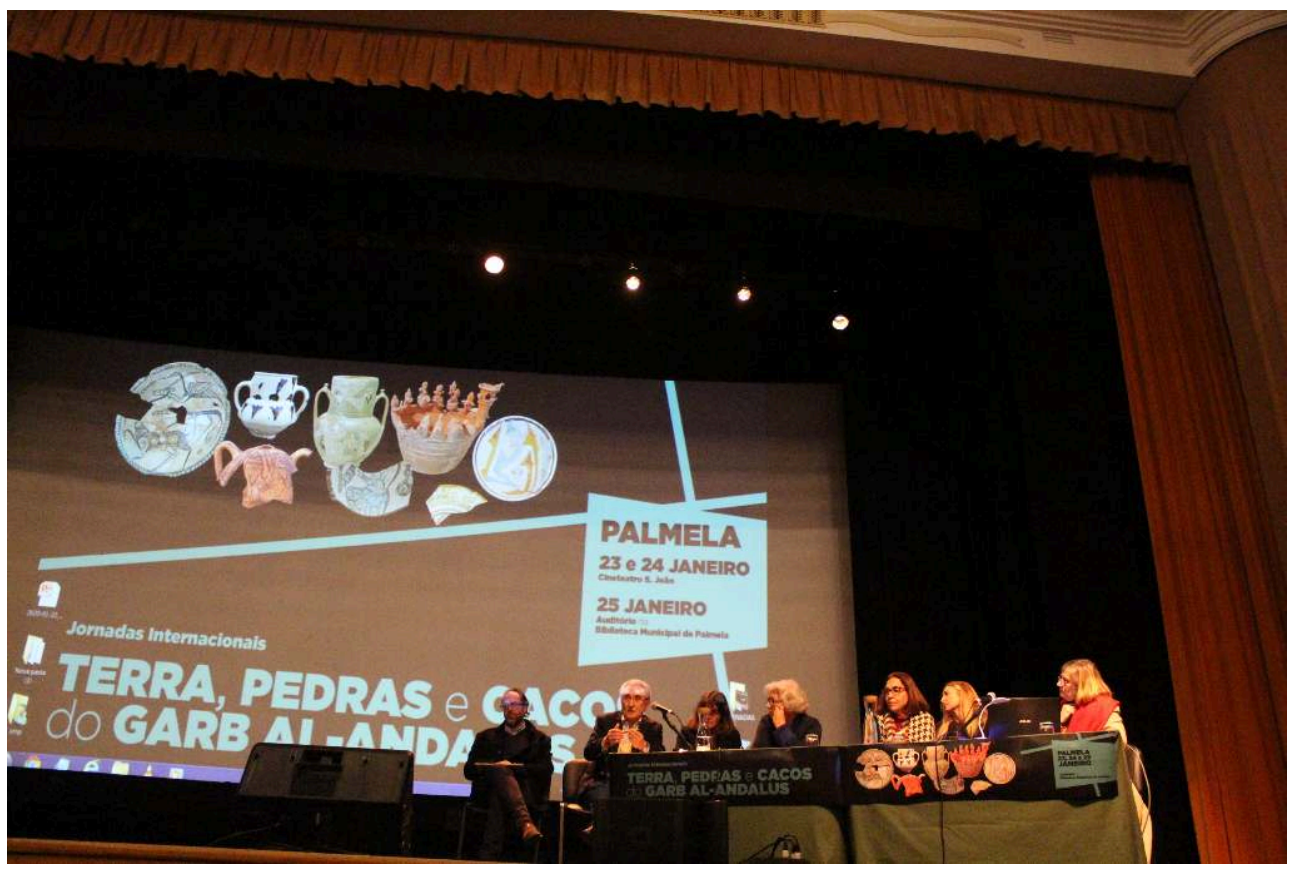

FIg. 1 - MOMENTO DE DEBATE DA SESSÃo 1.

(c) ISABEL CRISTINA FERNANDES

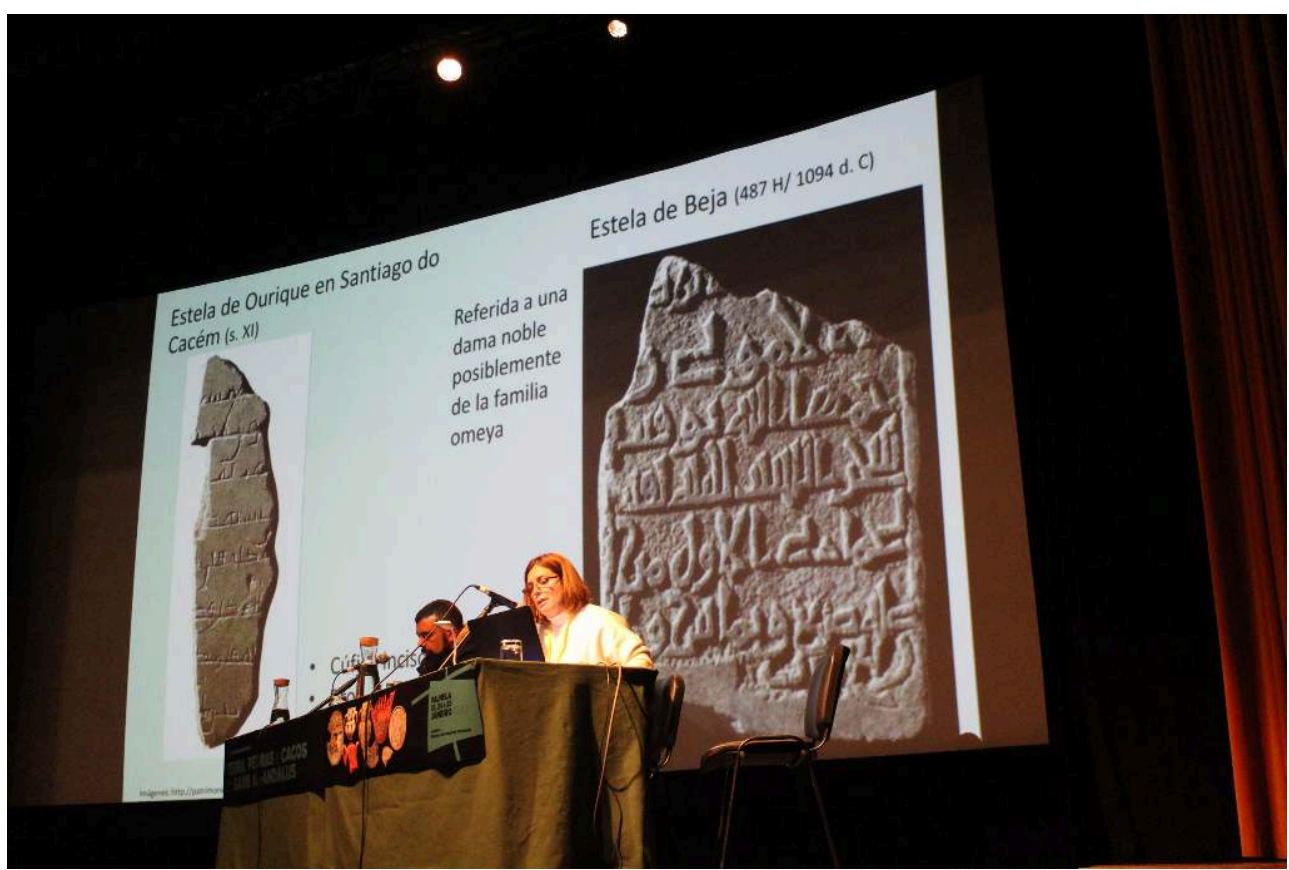

FIg. 2 - COMUNICAÇÃo de MARIA ANTÓNIA MARTíNEZ NúÑEZ E PILAR DELgADO BLASCO, APRESENTADA PELA SEgUNdA (SESSÃo 1).

(C) ISABEL CRISTINA FERNANDES

7 Trabalhos arqueológicos recentes proporcionaram várias abordagens com novidade: Maria José Gonçalves, Carlos Oliveira e Miguel Costa relançaram a discussão sobre a localização de espaços de culto na Xîlb islâmica, com base em novos dados arqueológicos apoiados em informação da documentação escrita; o estudo da atividade metalúrgica no sítio fortificado de Albalat (Cáceres, Espanha), através de estruturas, escórias e produções identificadas arqueologicamente, permitiu a Sophie Gilotte e 
Pauline De Keukelaere uma aproximação ao trabalho desenvolvido pelos ferreiros locais, às matérias e às técnicas que utilizaram; Teresa Ricou da Ponte, Luciana de Jesus e Vasco Abegoaria apresentaram estudo sobre numismas - felus emirais, provenientes do sítio da Quinta do Estácio 3, Beja, escavado em 2018 e onde se registaram vestígios romanos, tardo-antigos e emirais; no Alto da Vigia, em Colares, Sintra, onde antes se localizou um santuário romano, foram registados arqueologicamente uma mesquita, silos e uma necrópole, estruturas de um ribat muçulmano, descoberta transmitida a estas jornadas por Alexandre Gonçalves e Helena Catarino.

8 Através de posters, Fábio Capela informou sobre a ocupação emiral do castelo de Alferce e a intenção de avançar com um projeto de investigação arqueológica no local e Cézer Santos, Fernando Henriques e Nuno Barraca anunciaram a possível identificação de níveis de ocupação islâmica no Largo do Castelo da Bemposta (Penamacor), onde realizaram sondagens arqueológicas.

9 No capítulo da cerâmica islâmica, o Grupo CIGA, com Pilar Lafuente, realizou uma síntese sobre aspetos técnicos, estéticos e iconográficos dos ornamentos na cerâmica do Garb al-Andalus, procurando, através deles, uma crescente precisão das atribuições cronológicas. Para cerâmicas do século XIV da mouraria de Moura, Santiago Macias e José Valente deram a conhecer um conjunto de peças de produção local e algumas importações.

10 Várias arqueociências tiveram a sua representação nesta reunião, mostrando a importância do seu contributo para clarificar e completar a percepção das ocupações do período islâmico. Foram os casos: do estudo arqueométrico de um conjunto de cerâmica islâmica de Mértola (séculos X-XII), apresentado por Massimo Beltrame, Susana Gómez e José Mirão, com resultados para a proveniência e as tecnologias de produção; da reflexão crítica de Maria João Valente sobre o alcance dos estudos zooarqueológicos no Garb, através de uma metodologia de análise que permita chegar a modelos da utilização/gestão animal no período e no território em questão, e sobre o futuro da investigação das arqueofaunas. Ainda neste âmbito temático, expuseram-se três posters: um sobre as faunas medievais do castelo de Palmela (Cleia Detry e Isabel Fernandes), outro sobre análise multi-isotópica de material osteológico de necrópoles muçulmanas e cristãs de Évora (Rebecca Macroberts et. al.) e um terceiro sobre dieta e padrões de mobilidade através da análise de ossadas de necrópoles de Loulé e Cacela-aVelha (Judith López-Aceves et. al.).

11 A sessão 1 encerrou com uma abordagem inovadora de Bruno Almeida à questão da terminologia cerâmica, partindo de uma perspetiva linguística e conceptual e recorrendo à análise e à organização de terminologia multilingue, com o intuito de vir a criar um recurso terminológico a disponibilizar on-line.

12 A Sessão 2, focada nas ações e nos resultados da arqueologia preventiva, complementou a sessão anterior no que se refere a novas descobertas, logrando demonstrar o que a temática anunciava: a construção de mais e melhor conhecimento do Garb a partir deste tipo de ações.

13 O ponto de situação das intervenções de categoria C do período islâmico em Portugal, apresentado pelo Grupo CIGA, revelou que se realizaram, nos últimos 25 anos, 1500 intervenções arqueológicas nesta categoria, quais os seus principais condicionalismos e resultados, e destacou exemplos de especial relevância. 
14 Nos estudos de caso de maior abrangência geográfica, evidenciaram-se: a reflexão de Ricardo Costeira da Silva sobre Coimbra alto-medieval, partindo dos trabalhos realizados no antigo fórum e criptopórtico de Aeminium para ir revisitando vários outros locais de investigação arqueológica da cidade e problematizando até que ponto a salvaguarda tem revertido para conhecimento; o ponto de situação dos registos arqueológicos funerários de Mérida (sécs. VIII-XIII), por Miguel Alba, que proporcionou uma visão da organização, implantação e evolução das áreas funerárias e, através delas, da extensão e das dinâmicas de uma cidade de capital importância no Garb.

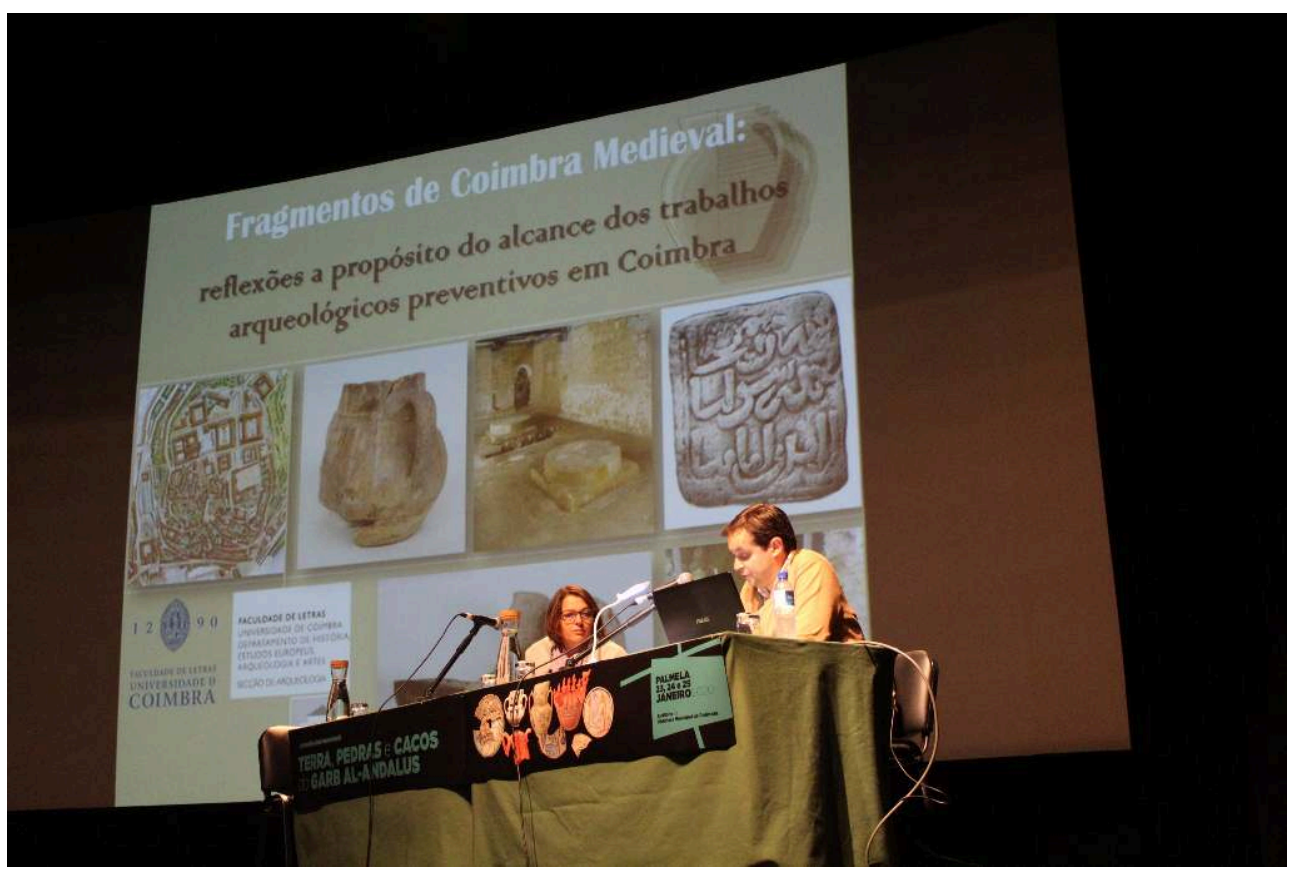

FIg. 3 - COMUNICAÇÃo dE RICARDO COSTEIRA DA SILVA (SESSÃo 2).

(c) ISABEL CRISTINA FERNANDES

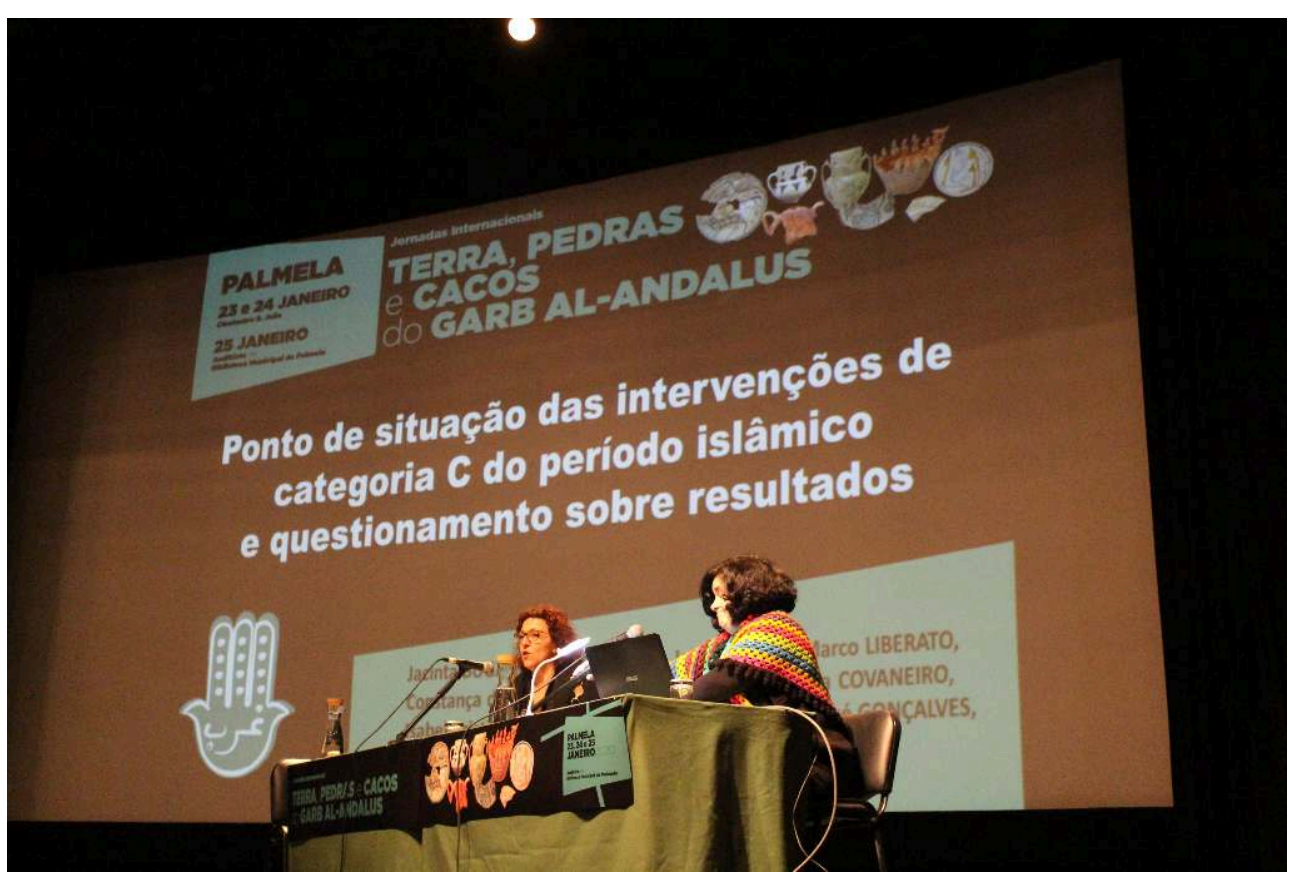

FIg. 4 - COMUNICAÇÃo dO GRUPO CIGA (SESSÃo 2).

(C) ISABEL CRISTINA FERNANDES 

investigações arqueológicas do período islâmico, originadas de planos de prevenção salvaguarda, algumas muito recentes e expressivas da riqueza dos achados. Neste grupo incluem-se: uma panorâmica, por Susana Duarte, Joaquina Soares e Carlos Tavares da Silva dos registos islâmicos em Setúbal, decorrentes de intervenções do Museu de Arqueologia do Distrito de Setúbal, entre os quais se inclui uma necrópole; o estudo de uma epígrafe funerária do século XII, também de Setúbal, da autoria de Artur Fontinha, M. Antónia Martínez Núñez e Maria João Cândido; os novos registos arqueológicos do castelo de Palmela, dados a conhecer por Luís Pereira e Michelle Santos, proporcionados por uma intervenção na encosta sul, e que incluem o registo de silos com abundantes materiais de finais da ocupação islâmica e início da portuguesa. período islâmico através da arqueologia: o de Carlos Oliveira e Maria José Gonçalves, sobre materiais arqueológicos de uma vasta área escavada na Rua da Arrochela (Silves) e o de Isabel Luzia et. al., sobre os banhos islâmicos de Loulé.

Neste grupo de comunicações que correspondem a descobertas recentes, Lisboa teve um enfoque especial, mostrando bem as dinâmicas de investigação arqueológica na cidade e as suas importantes aportações para o conhecimento da urbe medieval: dos Armazéns Sommer, intervencionados entre 2004 e 2016, foram apresentados por Paulo Rebelo, Vanessa Filipe, Ricardo Ribeiro, Virgílio Martínez e Nuno Neto, aspetos da evolução arquitetónica doméstica e defensiva, esta última com incidência na cisterna/ muralha desde a antiguidade tardia ao período islâmico; do Largo da Atafona (Lisboa), com intervenção em 2018, Vanessa Filipe, José Pedro Henriques, Vasco Vieira e Tiago Pereira apresentaram um estudo das cerâmicas islâmicas exumadas, procurando uma leitura da produção oleira de Lisboa nesse período; sobre os trabalhos na Praça da Figueira (escavações entre 1999 e 2001), Rodrigo Banha da Silva, André Bargão, Sara Ferreira, Inês Pires e Duarte Mira mostraram, através de uma síntese do estudo das cerâmicas provenientes de contextos do arrabalde ocidental da cidade, aspetos evolutivos entre o final das taifas e o período almorávida; por fim, Vanessa Filipe, Nuno Neto, José Pedro Henriques, Sara Brito, Alice Toso, Sílvia Casimiro, Raquel Granja, Joana Inocêncio e Sónia Ferro forneceram uma panorâmica da necrópole da área oriental da Lisboa islâmica, através de dados recolhidos nas escavações realizadas na Calçadinha do Tijolo, em 2014, no Largo do Sequeira, em 2016 a 2018 e no Largo de Santa Marinha, em 2019. Dois dos posters expostos eram também consagrados a Lisboa: o de Tânia Casimiro, Vanessa Filipe e José Pedro Henriques sobre escavações no Largo dos Lóios e análise do respetivo espólio, e o de Andreia Rodrigues, sobre os silos da igreja de S. Lourenço (Mouraria).

18 A Sessão 3, sobre os pontos de contacto entre o Garb e o Mediterrâneo, abriu com uma reflexão sobre Madina Mayürqa, de Guillermo Rosselló Bordoy, autor de primordiais estudos sobre cerâmica do al-Andalus. As relações entre o Garb e o Sharq através das cerâmicas foram tratadas por Rafael Azuar, que concluiu pela intensidade de contactos costeiros, entre o Atlântico e o Mediterrâneo, tanto ao nível económico como cultural, desde o califado omíada até ao período merínida (século XIV). Tocando igualmente a questão das relações das costas do Garb com o mundo mediterrânico, a comunicação de Cristina Tété Garcia e Patrícia Dores partiu da análise de cerâmicas do período almóada de Cacela-a-Velha. 


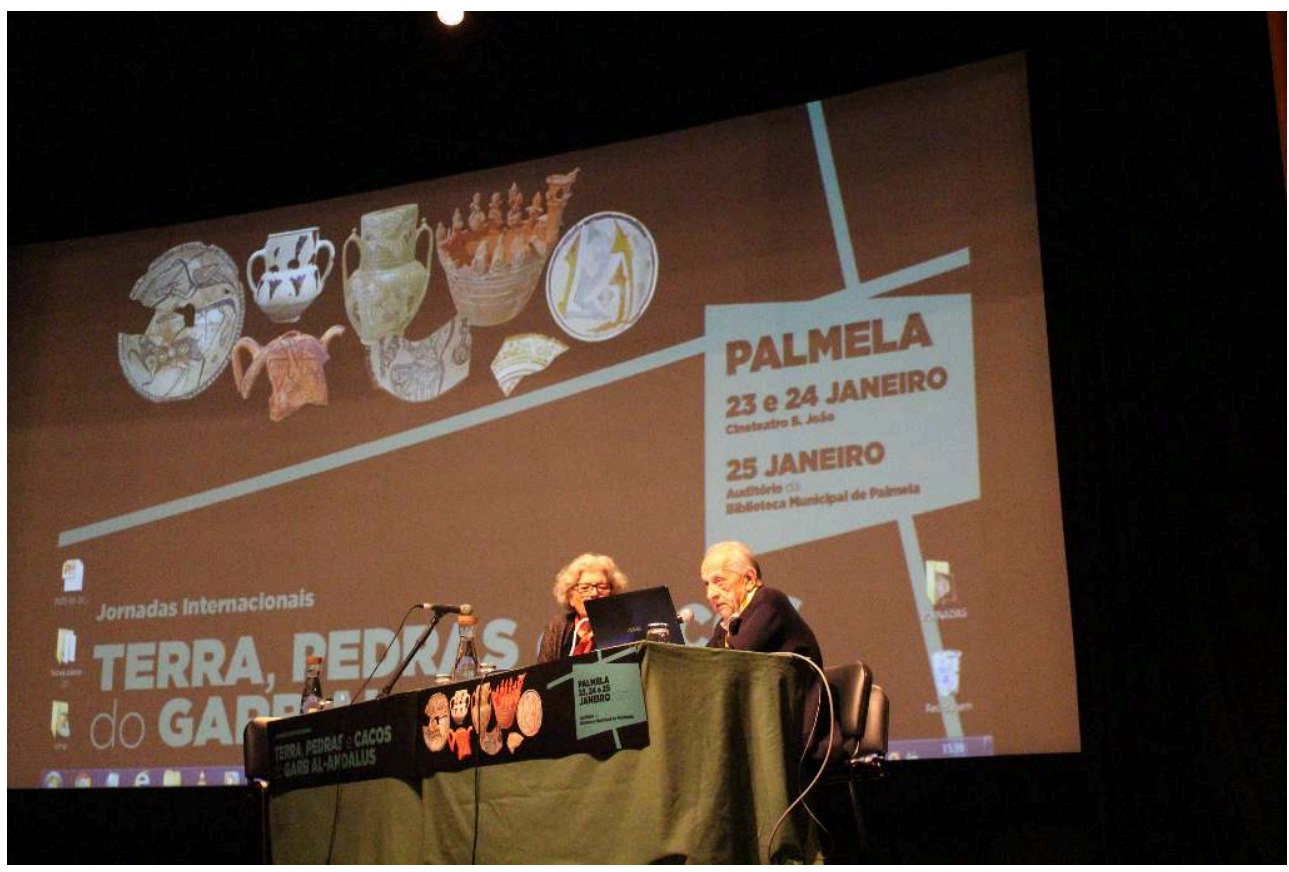

FIg. 5 - COMUNICAÇÃo dE GUILLERMO ROSSELLÓ BORDOY (SESSÃo 3).

(c) ISABEL CRISTINA FERNANDES

19 No que respeita às relações com o Norte de África, Yaiza Hernández Casas, Bilal Sarr e Luca Mattei propuseram-se apresentar um corpus, em construção, de cerâmica medieval das costas do Rif, incluindo produções berberes locais, valorizando os intercâmbios com o al-Andalus. Por seu lado, Fernando Villada e Rodrigo Álvarez González apresentaram materiais cerâmicos dos períodos califal, taifa e merínida de dois silos de Ceuta, estabelecendo afinidades com peças registadas no Garb.

20 A original abordagem de Patrice Cressier, sobre questões de imagem no al-Andalus, colocou em relevo aspetos usualmente menos trabalhados, como a relação entre a difusão da imagem e o seu suporte, a identificação do encomendante e dos difusores, as motivações dos destinatários, para além do questionamento sobre o significado do tema da imagem, nas suas diversas expressões, selecionando para o efeito a representação humana e animal. 


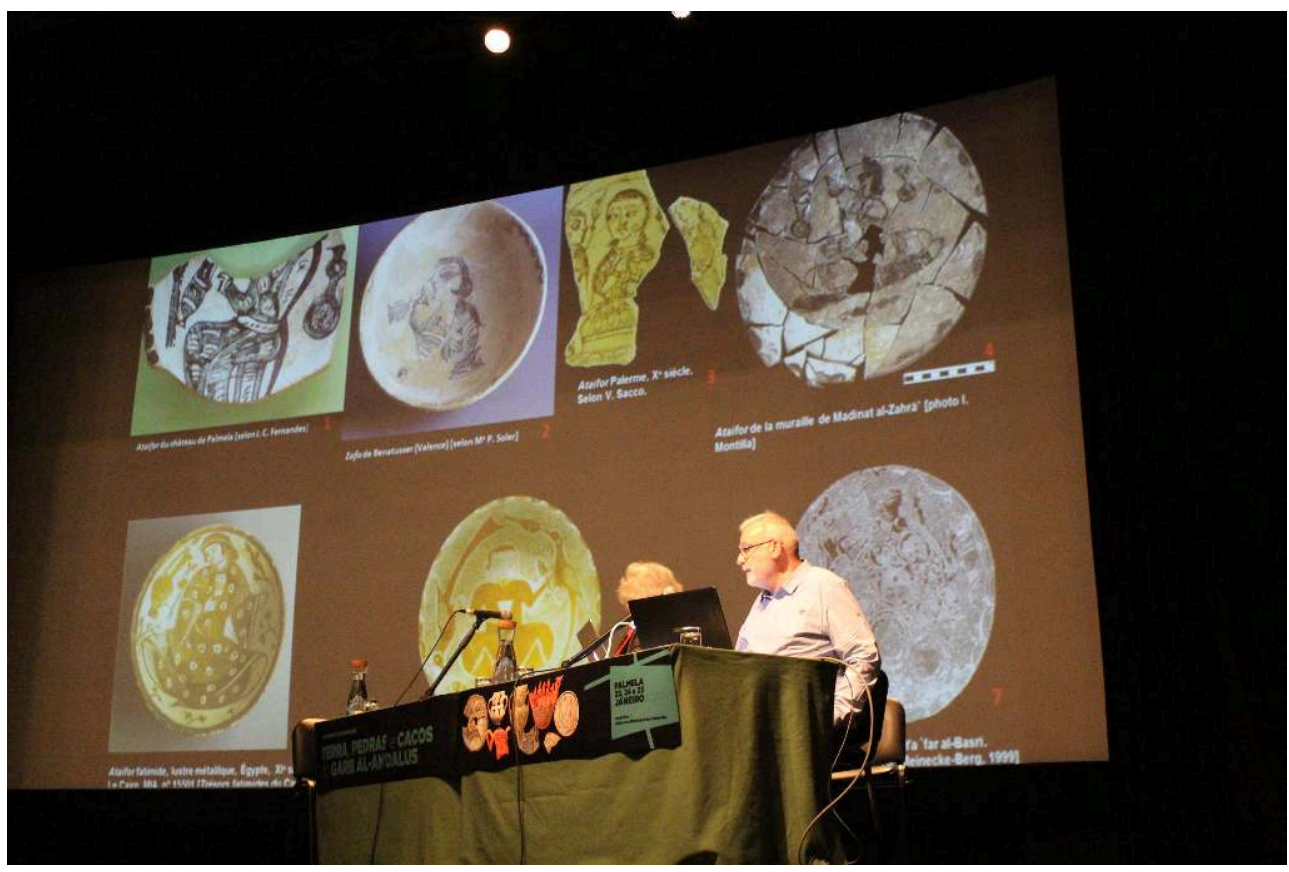

Fig. 6 - COMUNICAÇÃo de PATRICE CESSIER (SESSÃo 3).

(c) ISABEL CRISTINA FERNANDES

21 A Sessão 4 teve como propósito estimular abordagens de evidente interligação entre a história a arqueologia. José Avelino Gutiérrez mostrou como os avanços da investigação arqueológica estão a comprovar a importância da presença islâmica no Norte peninsular (Astúrias, Leão, Zamora) para a fase omíada inicial (711-722), correspondente a um impacto da conquista até há pouco não reconhecido e agora evidenciado, nomeadamente, nas estruturas defensivas de hispano-visigodos e muçulmanos. Alejandro García Sanjuan debruçou-se sobre a pertinente questão da relação entre Garb al-Andalus e Burtuqāl, provando, a partir das fontes árabes, que não existe entre eles uma identificação absoluta e como os nomes evoluiram na dimensão geográfica e, no caso de "Portugal”, também na dimensão política.

A região de entre Tejo e Sado contou com quatro comunicações neste apartado. Rui Gil e Rafael Santiago ensaiaram hipóteses sobre a Sesimbra almorávida, através da documentação escrita e de cerâmicas provenientes do castelo, que registaram como produções de Lisboa. Para o território entre Palmela e Alcácer do Sal, espaço de fronteira na segunda metade do século XII e primeiras décadas do XIII, Isabel Cristina Fernandes procurou desenhar aspetos da paisagem social e política, recorrendo às marcas materiais do quotidiano em articulação com as fontes escritas. Manuel Fialho fez um percurso pelas visões da historiografia ocidental em relação ao urbanismo islâmico, para se fixar na sua própria interpretação do modelo das cidades medievais hispano-muçulmanas, partindo do caso de Lisboa e fundamentando-se em dados arqueológicos e documentais. Filomena Barros transportou-nos aos bairros oleiros muçulmanos de Lisboa, permitindo-nos vislumbrar particularidades da tessitura social e económica do período pós-conquista portuguesa. Santarém esteve presente no poster de Javier Albarrán, que nos trouxe uma análise da ideologia de jihād na expedição almóada a esta cidade. 


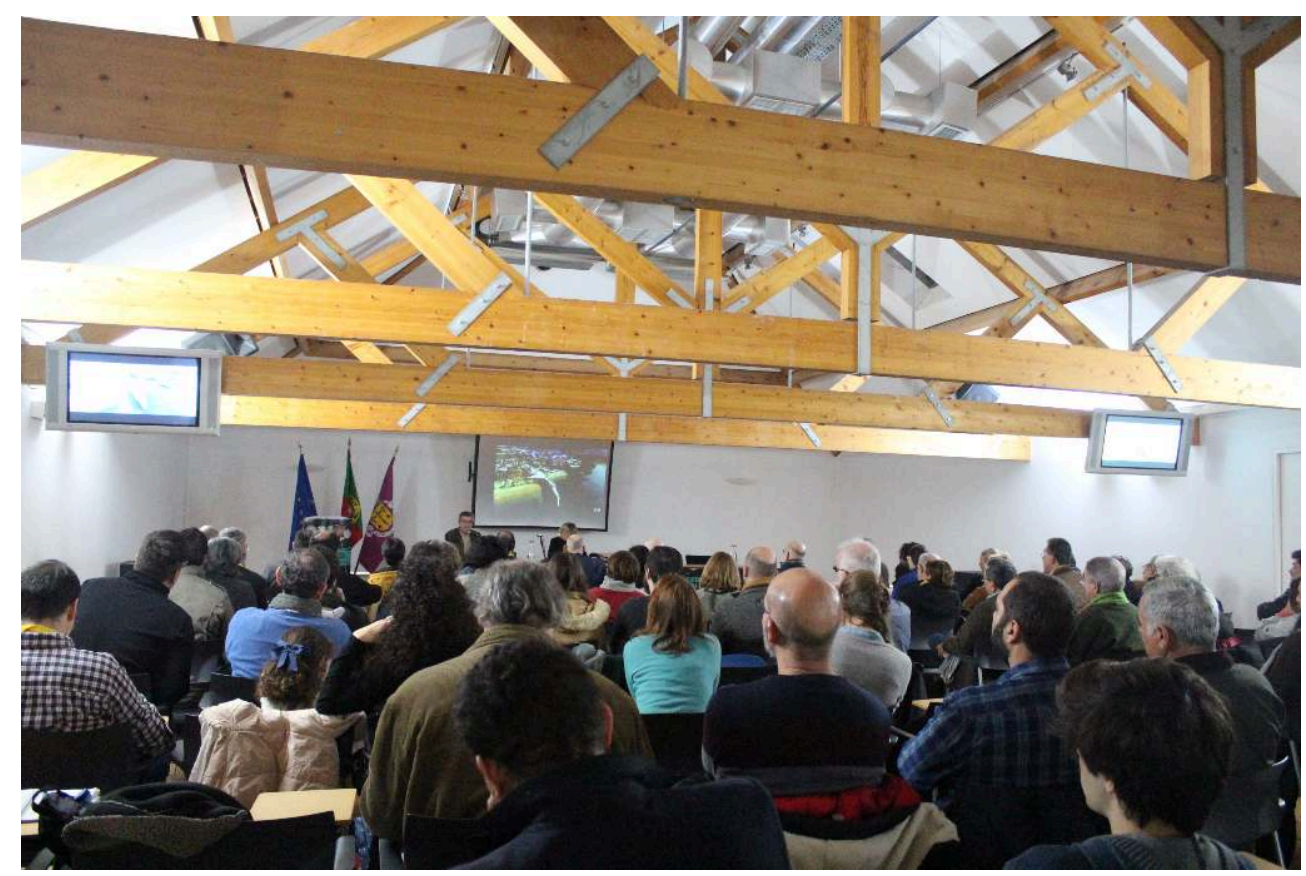

Fıg. 7 - SESSÃo 4, NO AUditório dA BIBLIOTECA de PALMELA.

(c) ISABEL CRISTINA FERNANDES

O sul do Garb foi também abordado por vários autores. A partir do Muqtabis de Ibn Hayyan, Fernando Branco Correia centrou-se na análise da revolta do berbere Mahmud Ibn al-Ğabbar e seguidores, na Mérida do século IX, seguindo a geografia dos seus movimentos para chegar a uma leitura de aspetos do quotidiano do grupo. Hermenegildo Fernandes explicou o projeto almóada de reocupação de Beja, com recurso a um variado leque de fontes muçulmanas e cristãs. Santiago Macias dedicou a sua intervenção à identificação de sítios do período islâmico, com base arqueológica no caso de Laqant (concelho de Moura) e a partir das fontes muçulmanas e da toponímia para a identificação de Halq az-Zawiya e de Kanisat al-Gurab, colocando como hipótese a sua correspondência, respetivamente, ao ribāṭ de Arrifana e à zona de Porches.

$\mathrm{Na}$ sessão de encerramento das jornadas, Cláudio Torres tomou a palavra para sublinhar o enquadramento mediterrânico do Garb e incitar a comunidade científica a prosseguir com afinco a investigação arqueológica e histórica do período islâmico no território português. 


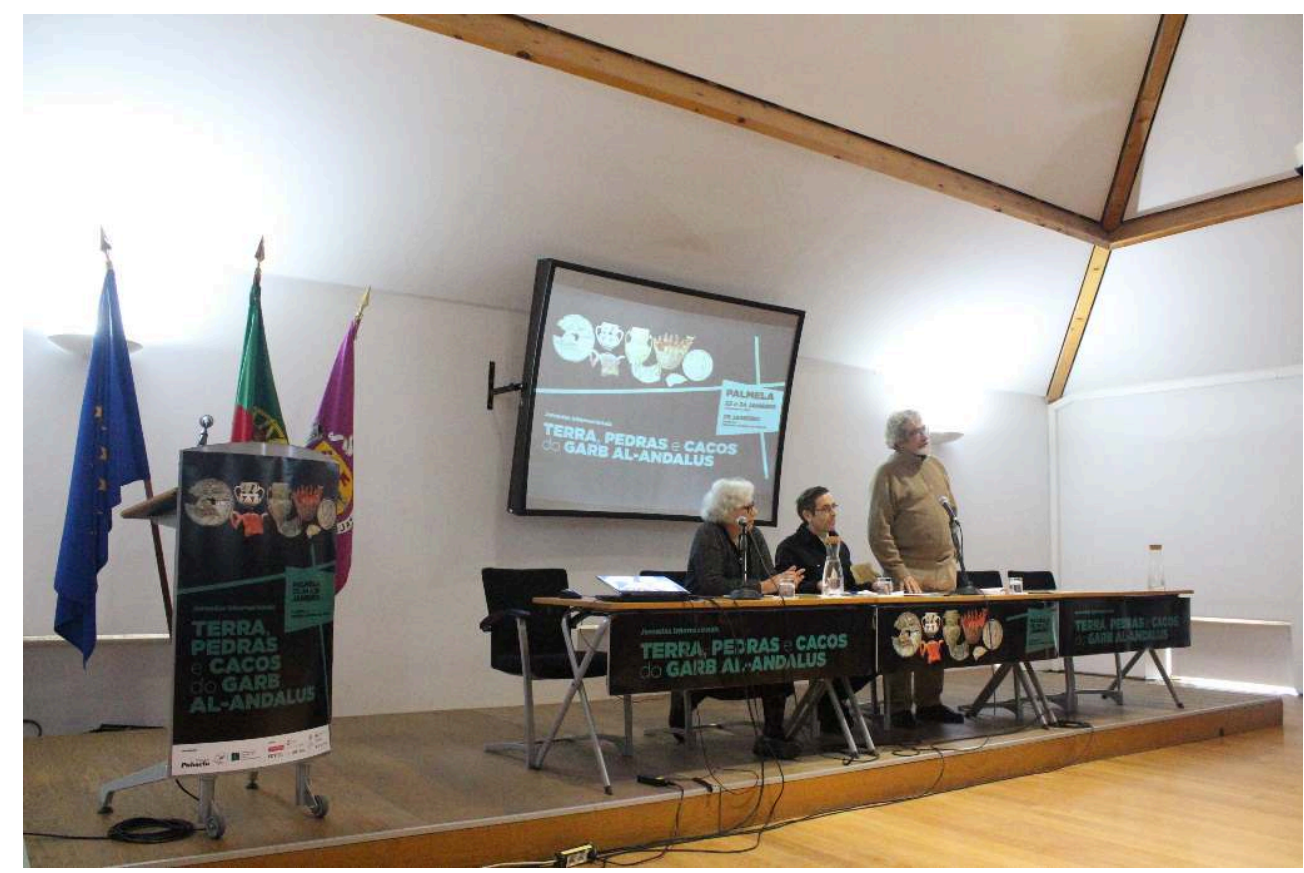

FIg. 8 - SESSÃo DE ENCERRAMENTO, COM INTERVENÇÃo dE CLÁUDIO TORRES.

(c) ISABEL CRISTINA FERNANDES

As visitas orientadas incluídas no programa deste evento completaram, de forma harmoniosa, a visão teórica dos estudos arqueológicos e permitiram conhecer de perto três importantes projetos de musealização de sítios intervencionados em Lisboa: os Armazéns Sommer, hoje o Lisboa Eurostars Museum, cuja visita foi guiada por Paulo Rebelo e Nuno Neto; o Núcleo de Interpretação da Muralha de D. Dinis - Museu do Dinheiro/Banco de Portugal, com percurso guiado por Artur Rocha; o núcleo arqueológico da Muralha Fernandina - Corpo Santo Hotel, com visita orientada por António Valongo.

Uma nota final para a apresentação de um livro, por André Teixeira, no final do segundo dia das jornadas: Scripta Manent. Inventario de Signos lapidarios de Ceuta / I. La ciudad, da autoria de Gabriel Fernández Ahumada e Fernando Villada Paredes, datado de 2017 e editado pela Ciudad Autónoma de Ceuta. A obra enquadra-se num projeto em curso, de recolha de marcas de canteiro e de grafitos traçados nos rebocos das muralhas de Ceuta, que resultou num inventário numeroso e muito significativo de exemplares, de que se publica o desenho e, nalguns casos, a leitura interpretativa. Os motivos dos grafitos aparecem ordenados nas seguintes categorias: antropomorfos, armamento, arquitetónicos, cordiformes, contas, elementos de localização, elementos de mira, emblemas, epigráficos, geométricos, navais, religiosos, vegetais, zoomorfos, tabuleiros de jogo e indeterminados. Nas palavras dos autores, estes signos “(...) são uma janela aberta (...) à vida quotidiana de homens e mulheres de outros tempos cujos nomes não figuram nos anais da história, que nos oferecem um valioso testemunho para compreender os seus anseios, inquietudes e, em definitivo, a sua forma de entender o mundo". 


\section{NOTAS}

1. GRUPO CIGA (Cerâmica Islâmica do Garb al-Andalus): FERNANDES, Isabel Cristina; GOMÉZ MARTÍNEZ, Susana; BUGALHÃO, Jacinta; CATARINO, Helena; CAVACO, Sandra; COVANEIRO, Jaquelina; GOMES, Ana Sofia; GONÇALVES, Maria José; INÁCIO, Isabel; LIBERATO, Marco; LOPES, Gonçalo; SANTOS, Constança.

\section{AUTOR}

\section{ISABEL CRISTINA FERNANDES}

Universidade Nova de Lisboa, Faculdade de Ciências Sociais e Humanas, Instituto de Estudos Medievais; Gabinete de Estudos sobre a Ordem de Santiago (Município de Palmela) 1070-312 Lisboa; 2954-001 Palmela, Portugal. isacrisff.ed@gmail.com. https://orcid.org/ 0000-0003-0725-7768 